The Open Civil Engineering Journal
CrossMark
Content list available at: www.benthamopen.com/TOCIEJ/
DOI: $10.2174 / 1874149501711010676$

RESEARCH ARTICLE

\title{
Bending Characteristics of a Post-Tensioned, Prestressed Concrete, Simply Supported Beam
}

\author{
Qingming Xiang ${ }^{1}$, Youliang Yang ${ }^{1}$, Jiaxuan $\mathrm{Su}^{1}$, Tianshu Yang ${ }^{1}$ and Xuansheng Cheng ${ }^{2, *}$ \\ ${ }^{\text {I}}$ WenZhou Traffic Quality Supervision Bureau, WenZhou, P.R. China \\ ${ }^{2}$ School of Civil Engineering, Lanzhou University of Technology, Lanzhou, P.R. China
}

Received: May 28, 2017

Revised: July 13, 2017

Accepted: July 19, 2017

\begin{abstract}
:
Introduction:

To analyze the basic, mechanical properties of post-tensioned, prestressed concrete, simply supported beams with grouting material of varied porosity under load, a finite element model is established by using ANSYS finite element software.
\end{abstract}

\section{Methods:}

The mid-span, cracking deflection and the equivalent stress of the prestressed, concrete beams with grouting material of varied porosity are calculated under different load forms.

\section{Results and Conclusion:}

The analysis results show that the cracking deflection of the prestressed, concrete beams increases with the increase in the porosity of the grouting material of the beams under different load forms. By contrast, under the same porosity grouting material, the cracking deflection of the symmetrical loads is larger than that of the uniform and concentrated loads. As the porosity of the grouting material increases, the peak value of equivalent stress decreases. The equivalent, stress-peak value of the concentrated load is always larger than the equivalent, stress-peak value under the uniform and symmetrical loads.

Keywords: Post-tensioned method, Prestressed concrete, Porosity of grouting material, Simply supported beam, Finite element, ANSYS.

\section{INTRODUCTION}

Due to national economic development and construction, low steel production, large demand, and tight supply, prestressed concrete structures have been utilized extensively in the field of civil engineering from the middle of the last century. After decades of research and engineering practice, prestressed concrete technology has matured. Prestressed concrete structures have many advantages. Prestressed concrete structures exhibit reduced cracking, increased seismic ductility, and optimized building functionality. At home and abroad, prestressed concrete structures are widely used in the field of civil engineering [1 - 3].

Since its development, many scholars at home and abroad have studied prestressed concrete. Padmarajaiah et al. [4] studied the cracking width of post-tensioned, prestressed, high-strength concrete beams. Nawy et al. [5] performed bending tests on 22, post-tensioned, unbounded, prestressed, high-strength, reinforced concrete beams. Huang et al. [6] conducted an experimental study on the prestressed, high-strength, lightweight, aggregate concrete, continuous, rigidframe bridge. The flexural performance of a post-tensioned, bonded, prestressed, reinforced, concrete beam with 500

* Address correspondence to this author at the School of Civil Engineering, Lanzhou University of Technology, Lanzhou, P.R. China; Tel: +86-931-2973784; E-mail: cxs702@126.com 
MPa steel bars was studied by Du [7] Kara et al. [8] studied the effect of load types and prestressing force on the effective moment of inertia and deflection of the beam by finite element analysis. Dong et al. [9] derived the deflection

formula of prestressed concrete beam through experimental study and theoretical analysis. However, this complex formula is not practical for application since it has a wide margin for error in calculation. The three-dimensional, finite element model of the bridge was established by Zhou et al. [10] by using ABAQUS software. The effect of prestressed steel bars on concrete was simulated by the temperature drop method. The numerical simulation of the bridge was carried out under a static load to test the effectiveness bridge prestressing analysis by the temperature drop method. Huang [11] primarily studied the finite elementmodeling method of the post-tensioned, prestressed concrete structure. The challenge of post-tensioned, prestressed concrete structure modeling is dealing with the interface between the concrete and prestressed tendons. Cao et al. [12] conducted two, static tests of post-tensioned, bonded, prestressed concrete beams in two stages of fatigue tests and analyzed the change in the nonlinear, dynamic characteristics of the beam's damage. Jia et al. [13] introduced the results of the bending test in the four-part, prestressed, ultra-high strength concrete beam to evaluate the effect of the prestressed, tendon depth and area on the bending behavior of the beam Liu et al. [14] developed a new three-segment beam model with local flexibilities at crack tips to investigate the vibration of a cantilever beam with a closed.

The study of the prestressed concrete, simply supported beam is well represented in the civil engineering field. Its performance can be comprehensively analyzed by theoretical calculation, experimental result, and finite element simulation. The finite element method is widely used in the construction industry and is applied to high-rise buildings, bridge design, roadbed paving, and slope engineering. The finite element analysis method will eventually replace the traditional experimental analysis method. ANSYS finite element software is currently used to study the relationship between the stress and strain of the prestressed concrete, simply supported beam under uniform load; the damage of the concrete by stress and strain; and the relationship between the load and displacement. It is primarily used for the finite element analysis of nonlinear structures in prestressed concrete.

The prestressed concrete, simply supported beam is one of the most widely used structures in reinforced concrete. Some scholars have conducted extensive research on prestressed concrete, simply supported beams. At home and abroad, the reinforced concrete structure has become an indispensable part of modern architecture. Currently, there are many studies on the mechanical properties of prestressed concrete, simply supported beams. The primary effects of varying types of reinforcement and concrete on the flexural failure of the prestressed concrete beam have been studied. Numerous conclusions have been drawn regarding the bearing capacity of prestressed concrete, simply supported beams. However, there are few studies involving the laws governing the cracking and equivalent stress of the posttensioned, prestressed concrete, simply supported beam with grouting materials of varied porosity.

In summary, as established by a comparative analysis of numerical simulations, this paper examines the model of the post-tensioned, prestressed concrete simply supported beam under different load forms. The laws regarding the cracking, deflection, and equivalent stress of the prestressed concrete beams with grouting materials of four different porosities (reserved void without grouting material, reserved void for filling $1 / 3$ grouting material, reserved void for filling $2 / 3$ grouting material, and full void) serve as a point of reference for the application of the prestressed beam.

\section{MATERIAL CONSTITUTIVE RELATION}

\subsection{Concrete Constitutive Relation}

The stress-strain relationship of concrete serves as the basis for calculating the strength of the reinforced concrete members, the internal force analysis of statically indeterminate structures, and the calculation of the structural ductility and finite element analysis of reinforced concrete. For decades, many scholars have devoted themselves to studying the nonlinear properties of the concrete compressive stress-strain relationship and exploring the reasonable, mathematical expression between stress and strain [14].

The stress-strain curve of concrete used in China for engineering application is the Hongnestad model [16]. The rising section of the model is the quadratic parabola and the descending section is the oblique line: 
Ascending segment:

$$
\sigma=f_{c}\left[2 \frac{\varepsilon}{\varepsilon_{0}}-\left(\frac{\varepsilon}{\varepsilon_{0}}\right)^{2}\right]
$$

Descending segment:

$$
\sigma=f_{c}\left[1-0.15 \frac{\varepsilon-\varepsilon_{0}}{\varepsilon_{u}-\varepsilon_{0}}\right]
$$

where fc is peak stress (the prism compressive strength); $\varepsilon_{0}$ is strain corresponding to peak stress, valued as $\varepsilon_{0}=$ 0.002 ; and $\varepsilon_{u}$ is ultimate compressive strain, valued as $\varepsilon_{u}$.

\subsection{Steel Bars Constitutive Relation}

In this paper, the bilinear hardening model is adopted for prestressed and non-prestressed reinforcement [15]. The stress-strain relationship of ideal, elastic-plastic is used for non-prestressed reinforcement. As shown in Fig. (1):

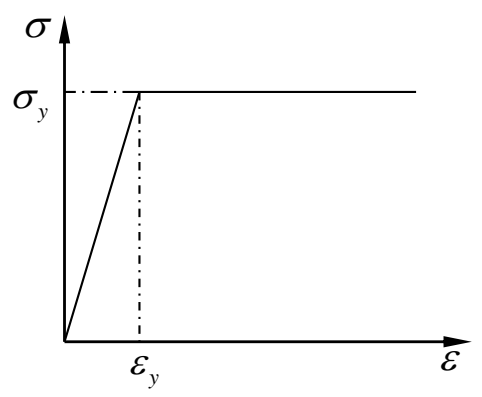

Fig. (1). Stress-strain relationship of common steel bars.

when,

$$
\varepsilon_{s} \leq \varepsilon_{y}, \sigma_{s}=E_{s} \varepsilon
$$

when,

$$
\varepsilon_{s}>\varepsilon_{y}, \sigma_{s}=f_{y}
$$

where $\varepsilon_{s}, \sigma_{s}, E_{s}$ are the strain, stress and elastic modulus of non prestressed reinforcement; and $\varepsilon_{y}, \sigma_{y}, f_{y}$ are the strain, stress, and yield stress of common steel bars.

The stress-strain relationship of prestressed reinforcement is shown in Fig. (2), it is assumed that the steel bar is pulled off when the stress reaches ultimate strength. Among them, $\varepsilon_{u}$, and $\sigma_{u}$ are the ultimate strain and ultimate tensile stress of prestressed reinforcement. $\varepsilon_{y}$ is the yield strain of prestressed reinforcement, and $0.75 \sigma_{u}$ is the yield stress of prestressed reinforcement:

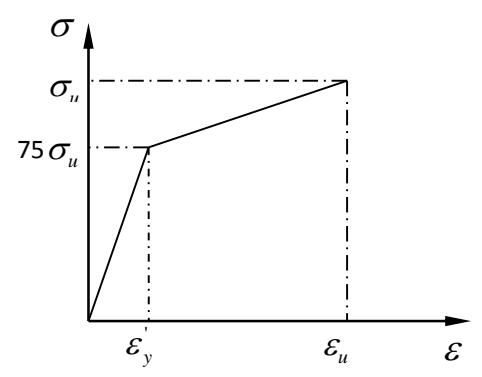

Fig. (2). Stress-strain relationship of prestressed reinforcement. 


\section{FINITE ELEMENT MODELING OF POST-TENSIONING PRESTRESSED CONCRETE BEAM}

\subsection{Calculation Parameters}

When using ANSYS finite element software to calculate and analyze the structure, the concrete parameters of post tensioned, prestressed concrete beam are obtained according to the material performance test: the uniaxial compressive strength is $40.3 \mathrm{MPa}$; the uniaxial tensile strength is $1.43 \mathrm{MPa}$; the elastic modulus is $3 \times 10^{4} \mathrm{MPa}$; Poisson's ratio is 0.2 ; and the per unit volume gravity of reinforced concrete is $25 \mathrm{kN} / \mathrm{m}^{3}$. The uniaxial stress-strain of concrete is calculated according to the formula of the concrete structure design code. The longitudinal tensile main bar is made of a hot-rolled, round, steel bar with a diameter of $10 \mathrm{~mm}$ and a yield strength of $300 \mathrm{MP}$. According to the requirements of the structure, the upper part of the beam is provided with 2, hot-rolled, round, steel bars with a diameter of $10 \mathrm{~mm}$ and a yield strength of $300 \mathrm{MPa}$. The stirrup adopts the hot-rolled, round, steel bar with a diameter of $6 \mathrm{~mm}$ and spacing of $100 \mathrm{~mm}$ and yield strength of $300 \mathrm{MPa}$. The prestressed steel wire with a diameter of $6 \mathrm{~mm}(1 \times 7-6)$ and tensile strength of $1270 \mathrm{MPa}$ adapts the linear layout, and the spacing, from the outer wall of the reserved void using metal bellows to the bottom of the beam, is $40 \mathrm{~mm}$. To calculate the model, the section of prestressed concrete beams is $150 \mathrm{~mm} \times 250$ $\mathrm{mm}$, the span is $2100 \mathrm{~mm}$, and the clear span is $1800 \mathrm{~mm}$. The load is divided into three types: concentrated loading, symmetrical loading, and uniform loading. The post-tensioned, prestressed concrete beams are divided into four cases: the reserved void without grouting material, the reserved void for filling $1 / 3$ grouting material, the reserved void for filling 2/3 grouting material, and the full void. The parameters selection of the prestressed tendon and the pipe combines with the material of the corrugated pipe. The friction coefficient, $\mu=0.3158$, the pipeline deviation coefficient, $\mathrm{k}=0.0015$, and the material parameters are shown in Table $\mathbf{1}$.

Table 1. material parameters.

\begin{tabular}{|c|c|c|c|c|}
\hline Material & Specifications & Unit & $\begin{array}{c}\text { Elastic modulus } \\
(\text { MPa) }\end{array}$ & Poisson ratio \\
\hline Concrete & $30 \mathrm{MPa}$ & Solid65 & $3 \times 10^{4}$ & 0.2 \\
\hline \multirow{2}{*}{ Common reinforcement } & $10 \mathrm{~mm}$ & Link180 & $2 \times 10^{5}$ & 0.25 \\
\cline { 2 - 5 } & $6 \mathrm{~mm}$ & Link180 & $2 \times 10^{5}$ & 0.25 \\
\hline Prestressed reinforcement & $6 \mathrm{~mm}(1 \times 7-6)$ & Link 180 & $1.95 \times 10^{5}$ & 0.3 \\
\hline
\end{tabular}

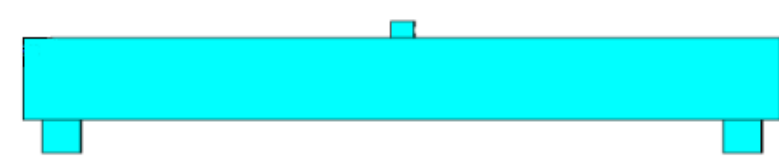

(a) concentrated load model

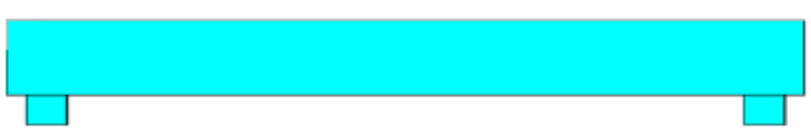

(b) uniform load model

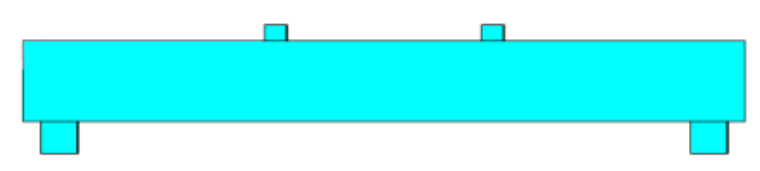

(b) symmetrical load model

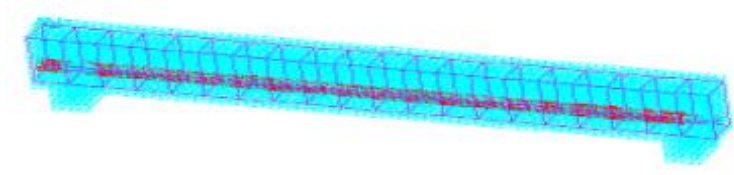

(d) steel skeleton model

Fig. (3). Finite element model.

\subsection{The Model Establishment}

The finite element model of post-tensioned, prestressed concrete beams is shown in Fig. $\mathbf{3}$ and is composed of concentrated, symmetrical, and uniform loading. The finite element model adopts a separate model and includes the concrete unit; the common reinforcement unit; the prestressed, reinforcement unit; and the adopt Solid65 unit. The Solid65 unit is used to simulate the concrete, rock, and other compressive capacity, which is much greater than the tensile capacity of the heterogeneous material. The Solid65 unit is based on a conventional, 8 node, three-dimensional, isoparametric element and is added to the concrete material parameters and integral reinforcement model. The prestressed and common bars are a slender material that can typically be neglected in transverse, shear strength. Thus, 
the prestressed and common bars can adapt unit Link180. This is called the 3D finite strain rod unit and consists of two nodes with each node having 3 degrees of freedom. The translational displacements run along the $\mathrm{X}, \mathrm{Y}$, and $\mathrm{Z}$ directions of the joint and can withstand axial tension but cannot bear bending moment. The bond between the prestressed steel wire and concrete is simulated by the Combin 14 unit; the bond coupling of prestressed, steel wire; and the concrete in three directions. The bonding effect between prestressed steel wire and concrete can be simulated by adjusting the elastic coefficient of the Combin14 unit. The influence of the grouting quality on the beam can then be obtained.

For the finite element mesh division, the length of the beam is divided into 42 sections. Each section length is 50 $\mathrm{mm}$. The cross section is divided into 60 squares with a length of $25 \mathrm{~mm}$. The concrete beam is divided into 2520 units. The boundary condition of the prestressed concrete, model beam is simply supported at both ends. In the calculation of the finite element model, the self-weight, prestress, and load applied to the upper part of the beam are considered:

\section{THE CALCULATION RESULTS ANALYSIS}

\subsection{Deflection Analysis}

Under concentrated, symmetrical, and uniform loads, the cracking deflection nephogram of the post-tensioned, prestressed concrete beams is shown under the four conditions (the reserved void without grouting material, the reserved void for filling $1 / 3$ grouting material, the reserved void for filling 2/3 grouting material, and the full void) in Figs. (4-6).

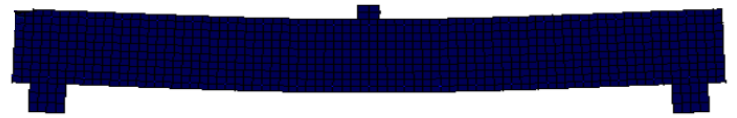

(a) 1/3 grouting material (Maximum displacement 0.351906 )

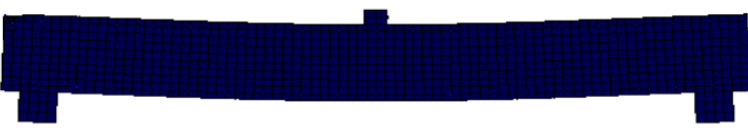

(c) without grouting material (Maximum displacement 0.349756)

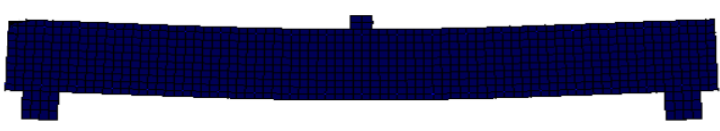

(b) 2/3 grouting material (Maximum displacement 0.353119)

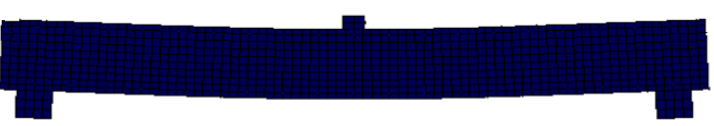

(d) full grouting material (Maximum displacement 0.354397)

Fig. (4). Deflection nephogram under concentrated load.
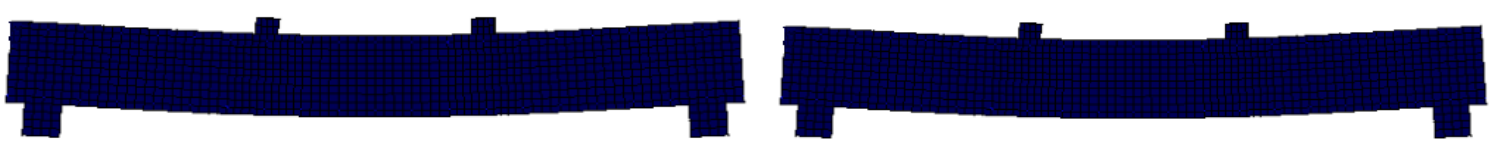

(a) without grouting material (Maximum displacement 0.421637) (b) 1/3 grouting material (Maximum displacement 0.422762)

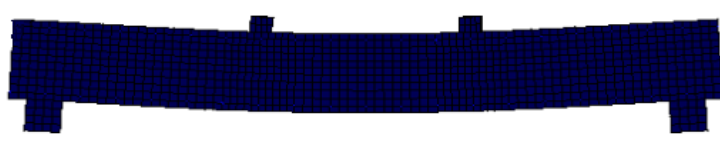

(c) full grouting material (Maximum displacement 0.424242)

Fig. (5). Deflection nephogram under symmetrical load.

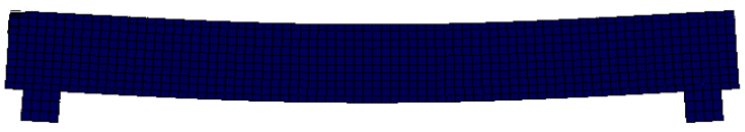

(a) without grouting material (Maximum displacement 0.419931)

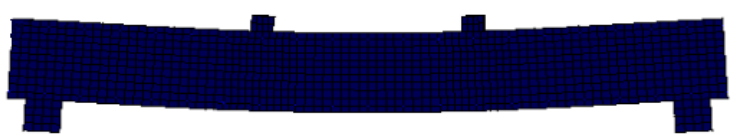

(d) 2/3 grouting material (Maximum displacement 0.423947)

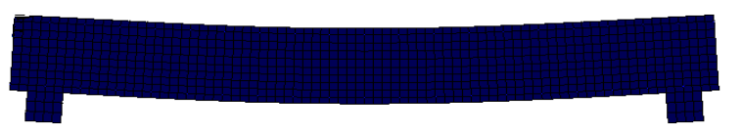

(b) 1/3 grouting material (Maximum displacement 0.418826 )

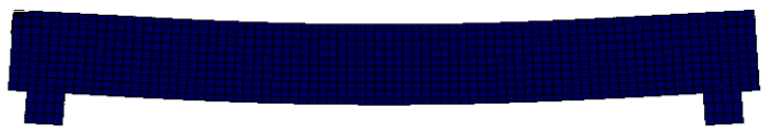

(c) full grouting material (Maximum displacement 0.42144)

(d) 2/3 grouting material (Maximum displacement 0.421099)

Fig. (6). Deflection nephogram under uniform load. 
As seen from Figs. (4-6), under the concentrated, symmetrical, and uniform loads, the post-tensioned, prestressed concrete simply supported beam has different cracking deflection values with grouting materials of varied porosity. As seen in the cracking deflection values shown in Table 2, under the same load, the value of the cracking deflection increases with an increase in porosity.

\subsection{Equivalent Stress Analysis}

Under concentrated, symmetrical, and uniform loads, the equivalent stress nephogram of the post-tensioned, prestressed concrete beams is shown under the four conditions (the reserved void without grouting material, the reserved void for filling $1 / 3$ grouting material, the reserved void for filling $2 / 3$ grouting material, and the full void) in Figs. (7-9).

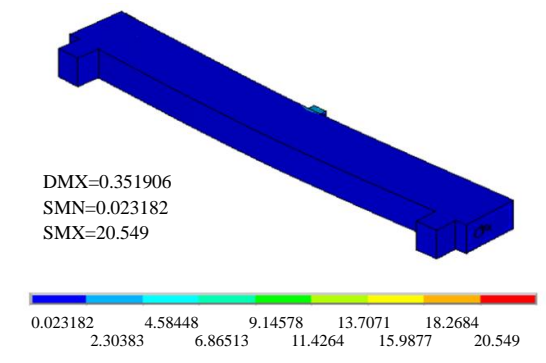

(a) $1 / 3$ grouting material

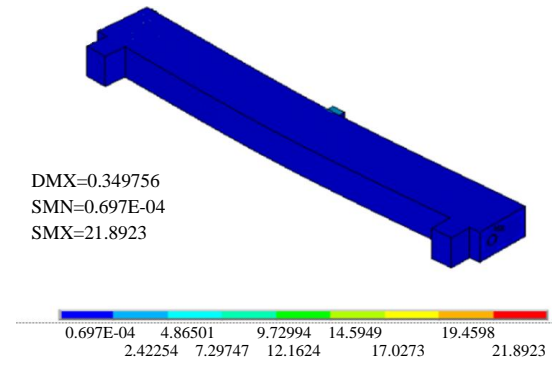

(c) without grouting material

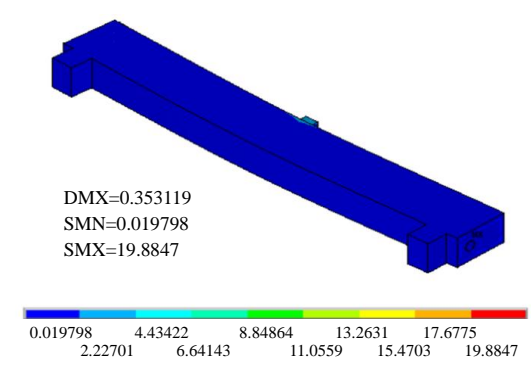

(b) $2 / 3$ grouting material

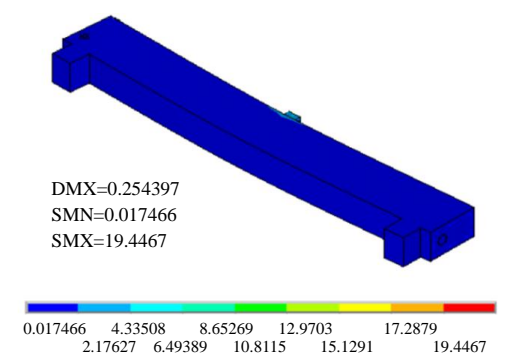

(d) full grouting material

Fig. (7). Equivalent stress nephogram under concentrated load.

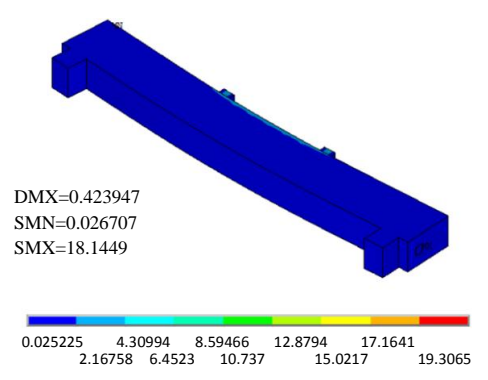

(a) $1 / 3$ grouting material

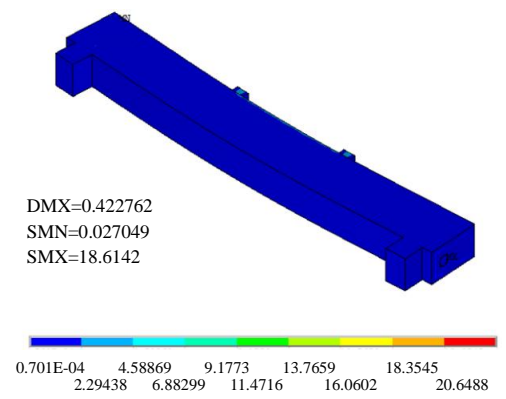

(c) without grouting material

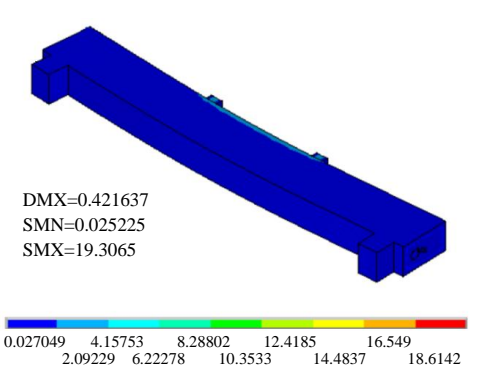

(b) $2 / 3$ grouting material

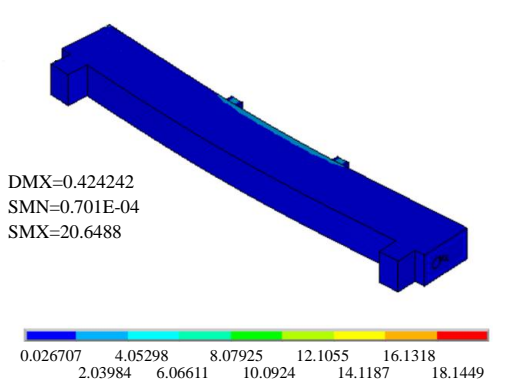

(d) full grouting material

Fig. (8). Equivalent stress nephogram under symmetrical load. 


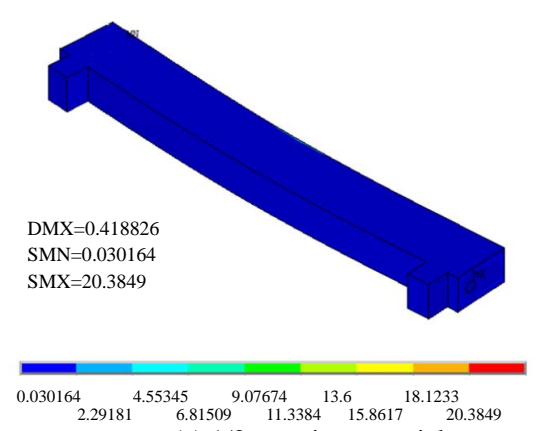

(a) $1 / 3$ grouting material

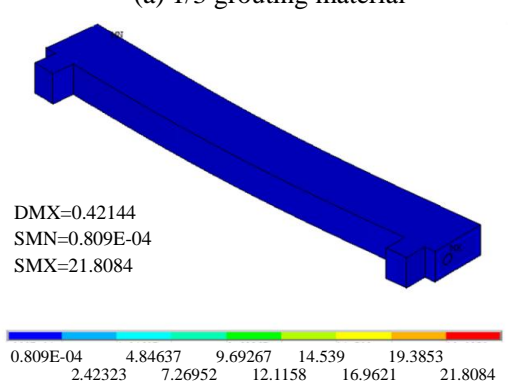

(c) without grouting material

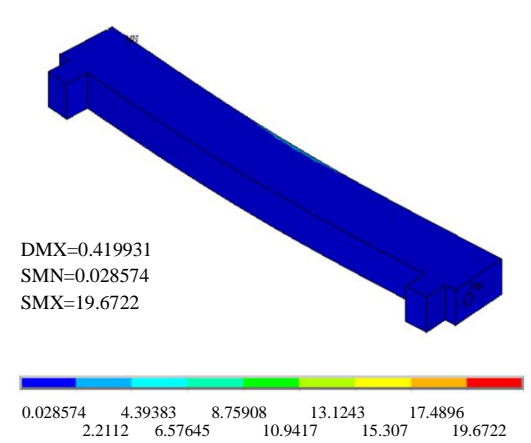

(b) $2 / 3$ grouting material

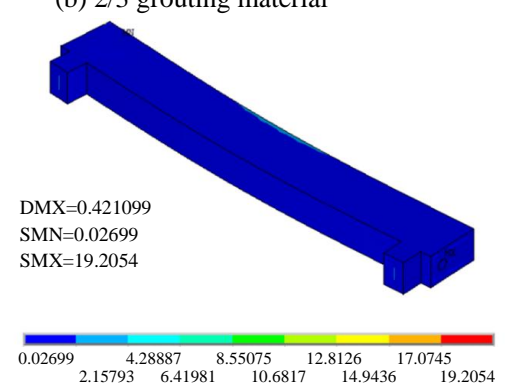

(d) full grouting material

Fig. (9). Equivalent stress nephogram under uniform load.

Table 2. Cracking deflection of beams with different porosity of grouting material under loads.

\begin{tabular}{|c|c|c|c|c|}
\hline \multirow{2}{*}{ Load Type } & \multicolumn{4}{|c|}{ Cracking deflection value of different densities (mm) } \\
\cline { 2 - 5 } & $\mathbf{1 / 3}$ Grouting Material & $\mathbf{2 / 3}$ grouting material & without grouting material & full grouting material \\
\hline Concentrated Load & 0.352 & 0.353 & 0.350 & 0.354 \\
\hline Symmetrical Load & 0.423 & 0.424 & 0.422 & 0.424 \\
\hline Uniform Load & 0.420 & 0.421 & 0.419 & 0.421 \\
\hline
\end{tabular}

As seen from Figs. (7-9), under concentrated, symmetrical, and uniform loads, the equivalent stress peak of the prestressed concrete, simply supported beam with grouting material of varied porosity appears in the upper middle position of the simply supported beam. According to the peak value of equivalent stress in Table (3), the peak value of equivalent stress decreases with an increase in the porosity of the grouting material in the same load form.

Table 3. Equivalent stress peak of beam with different porosity of grouting material under loads/MPa.

\begin{tabular}{|c|c|c|c|c|}
\hline \multirow{2}{*}{ Load Type } & \multicolumn{4}{|c|}{ Equivalent stress peaks for different densities } \\
\cline { 2 - 5 } & $\mathbf{1 / 3}$ grouting material & $\mathbf{2 / 3}$ grouting material & without grouting material & full grouting material \\
\hline Concentrate load & 20.549 & 19.885 & 21.892 & 19.447 \\
\hline Symmetrical load & 19.306 & 18.614 & 20.649 & 18.145 \\
\hline Uniform load & 20.385 & 19.672 & 21.808 & 19.205 \\
\hline
\end{tabular}

\subsection{Comparative Analysis of Results}

The comparison of the cracking deflection of prestressed concrete beams with grouting material of varied porosity under different load forms is shown in (Fig. 10).

As seen from Fig. (10), no matter the type of load form, the cracking deflection of the beam is increased with an increase in the porosity of the grouting material. Under the same porosity of the grouting material, the cracking deflection of the symmetrical load is larger than the cracking deflection under the uniform load. The concentrated load and cracking deflection under the concentrated load is the smallest. The greater the porosity of the grouting material of the post-tensioned, prestressed concrete beams, the higher the cracking load and bearing capacity are, and the greater the cracking deflection is. Additionally, under the concentrated load, the cracking load and deflection of the beam are the smallest. 


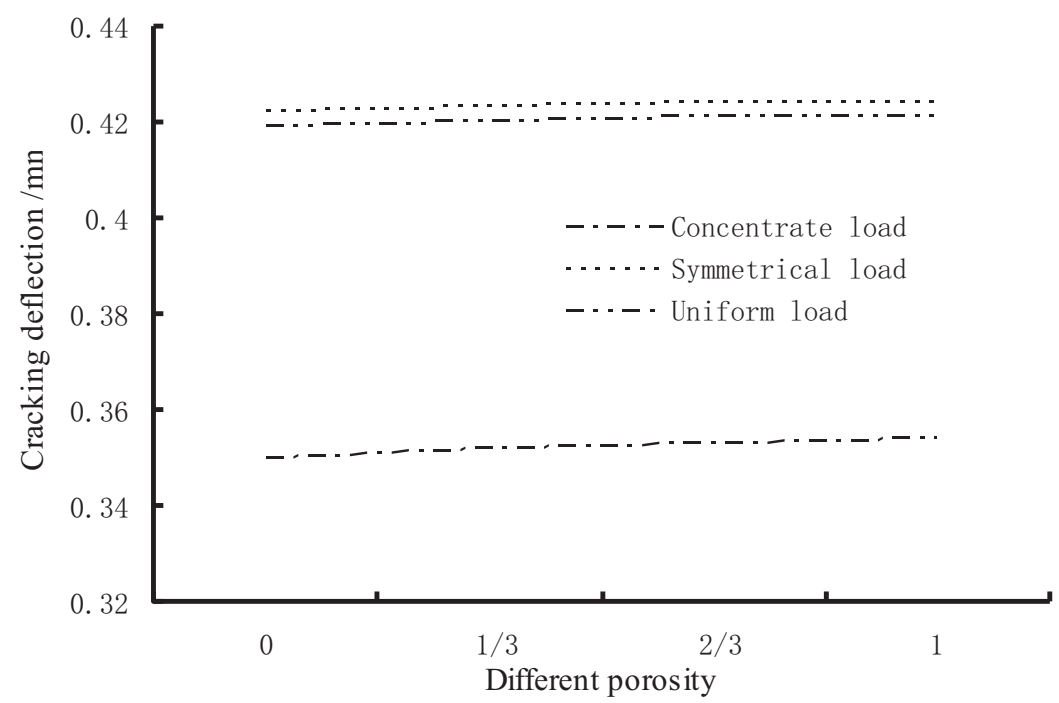

Fig. (10). Comparison of cracking deflection under different load forms.

The comparison of the equivalent stress peaks of the prestressed concrete beams with grouting material of varied porosity under different load forms is shown in Fig. (11).

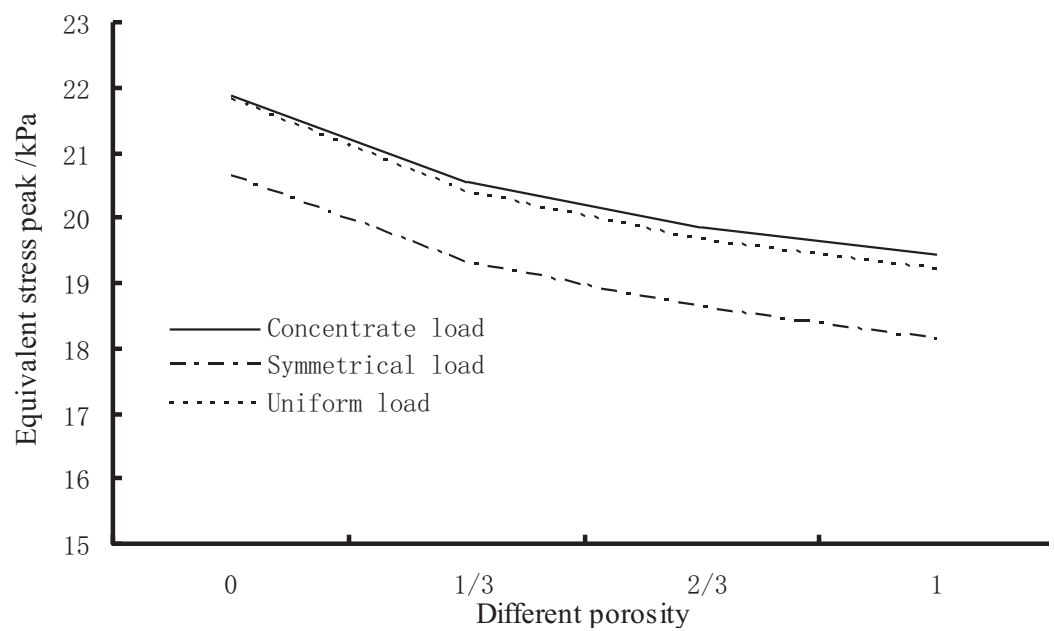

Fig. (11). Comparison of equivalent stress under different load forms.

As seen from Fig. (11), no matter what kind of load forms, the peak values of the equivalent stress of the beam lessen with an increase in the porosity of the grouting material. With grouting material of the same porosity, the equivalent stress peak value of the concentrated load is always larger than that of the uniform and symmetrical loads, and the equivalent stress peak value is close to the concentrated and uniform loads.

\section{CONCLUSION}

1. The cracking load, cracking deflection, and equivalent stress of the post-tensioned, prestressed concrete beams under grouting material of the same porosity vary due to the different load forms.

2. Under the concentrated, symmetrical, and uniform loads, the cracking deflection of the post-tensioned, prestressed concrete beam increases with an increase in the porosity of the grouting material.

3. With the increase in the porosity of the grouting material, the cracking deflection of the symmetrical load is always larger than the cracking deflection under uniform and concentrated loads, and the cracking deflection under the concentrated load is always at minimum. The results show that under a concentrated load, the cracking load of the beam is small and that a sudden, concentrated load on the upper part of the prestressed beam should be avoided. 
4. Under the action of concentrated, symmetrical, and uniform loads, the equivalent stress peak of post-tensioned, prestressed concrete beam decreases with an increase the porosity of the grouting material.

5. With grouting material of the same porosity, the equivalent stress peak value of the concentrated load is always greater than the equivalent stress peak value under the uniform and symmetrical loads. This further illustrates the conclusions drawn (2).

\section{CONFLICT OF INTEREST}

The authors declare no conflict of interest, financial or otherwise.

\section{ACKNOWLEDGEMENTS}

This paper is a part of Science and technology project Zhejiang Traffic Quality Supervision Bureau in China (Grant number: ZJ201602).

\section{REFERENCES}

[1] Z.X. Guo, "New development of prestress technology", Construction Technoloy, vol. 32, no. 7, pp. 6-8, 2003.

[2] L.G. Wang, and L. Liu, Modern prestressed structure design., Harbin Institute of Technology Press, 2009.

[3] W. Li, "Application of post-tensioning method in the construction of bonded prestressed", Intelligent city IC., pp. 85-89, 2016.

[4] S.K. Padmarajaiah, and A. Ramaswamy, "Crack-width prediction for high-strength concrete fully and partially prestressed beam specimens containing steel fibers", Aci Structural Journal, vol. 98, pp. 852-861, 2001.

[5] E.G. Nawy, "Flexural crackinging behavior of pretensioned and post-tensioned beams", ACI Structural Journal, vol. 82, pp. 890-900, 1985.

[6] S.N. Huang, Y.K. Liu, and L.P. Ye, "Experimental study on prestressed-high-strength-light-wetght-concrete continuous rigid frame bridge", Engineering Mechanics, vol. 24, pp. 134-140, 2007.

[7] M.M. Du, Flexural behavior of post-tensioned bonded prestressed concrete beams with 500mpa steel bars., Tongji University: Shanghai, pp. $48-59,2010$.

[8] I.F. Kara, and C. Dundar, "Effect of loading types and reinforcement ratio on an effective moment of inertia and deflection of a reinforced concrete beam", Advances in Engineering Software, vol. 40, pp. 836-846, 2009. [http://dx.doi.org/10.1016/j.advengsoft.2009.01.009]

[9] S.Y. Dong, Experimental study on deflection model of prestressed concrete simply supported beam after crackinging., Chang'an University, 2010 .

[10] Q. Zhou, and X.C. Zhang, "Static load test and numerical analysis of post-tensioning pre-stressed concrete bridge", Journal of Wuhan University of Technology, vol. 37, pp. 112-115, 2015.

[11] Y. Huang, Finite element method for post-tensioned prestressed concrete structures., Dissertations \& Theses-Gradworks, 2012.

[12] H. Cao, X. Zheng, J.M. Hua, and Z.M. Hu, "Damage detection of prestressed concrete beamsbased on nonlinear dynamic characteristics", Engineering Mechanics, vol. 31, pp. 190-194, 2014.

[13] J. Jia, and G. Meng, "Experimental study on flexural behavior of post-tensioning bonded partially prestressed ultra-high strength concrete beams", Journal of Harbin Institute of Technology (English Edition), vol. 22, pp. 94-102, 2015.

[14] J. Liu, W.D. Zhu, P.G. Charalambides, Y.M. Shao, Y.F. Xu, and X.M. Fang, "A dynamic model of a cantilever beam with a closed, embedded horizontal crack including local flexibilities at crack tips", In: Journal of Sound and Vibration, 2012, pp. 274-290.

[15] Y. Huang, "Finite element method for post-tensioned prestressed concrete structures", Dissertations \& Theses-Gradworks, 2012.

[16] Code for design of concrete structures. China, GB 50010-2010.

\section{(C) 2017 Xiang et al.}

This is an open access article distributed under the terms of the Creative Commons Attribution 4.0 International Public License (CC-BY 4.0), a copy of which is available at: https://creativecommons.org/licenses/by/4.0/legalcode. This license permits unrestricted use, distribution, and reproduction in any medium, provided the original author and source are credited. 